\title{
Gene expression profiling of NB4 cells following knockdown of nucleostemin using DNA microarrays
}

 \\ ${ }^{1}$ Department of Laboratory, The First Affiliated Hospital of Zhengzhou University; ${ }^{2}$ Department of Laboratory, \\ The First Affiliated Hospital of Henan University of TCM; ${ }^{3}$ Faculty of Laboratory Medicine, \\ Zhengzhou University; ${ }^{4}$ The Key-Disciplines Laboratory Clinical Medicine in Henan Province; \\ ${ }^{5}$ Key Lab of Clinical Laboratory Medicine of Henan Province, Zhengzhou, Henan 450052, P.R. China
}

Received December 23, 2014; Accepted December 18, 2015

DOI: $10.3892 / \mathrm{mmr} .2016 .5213$

\begin{abstract}
Nucleostemin (NS) is mainly expressed in stem and tumor cells, and is necessary for the maintenance of their self-renewal and proliferation. Originally, NS was thought to exert its effects through inhibiting p53, while recent studies have revealed that NS is also able to function independently of p53. The present study performed a gene expression profiling analysis of p53-mutant NB4 leukeima cells following knockdown of NS in order to elucidate the p53-independent NS pathway. NS expression was silenced using lentivirus-mediated RNA interference technology, and gene expression profiling of NB4 cells was performed by DNA microarray analysis. A total of 1,953 genes were identified to be differentially expressed (fold change $\geq 2$ or $\leq 0.5$ ) following knockdown of NS expression. Furthermore, reverse-transcription quantitative polymerase chain reaction analysis was used to detect the expression of certain candidate genes, and the results were in agreement with the micaroarray data. Pathway analysis indicated that aberrant genes were enhanced in endoplasmic, c-Jun N-terminal kinase and mineral absorption pathways. The present study shed light on the mechanisms of the p54-independent NS pathway in NB4 cells and provided a foundation for the discovery of promising targets for the treatment of p53-mutant leukemia.
\end{abstract}

\section{Introduction}

In 2002, nucleostemin (NS) was detected in the nucleoli of early pluripotent cells, and was found to be associated with cell proliferation; it is also crucial for supporting the

Correspondence to: Professor Baohong Yue, Department of Laboratory, The First Affiliated Hospital of Zhengzhou University, 1 Jianshe East Road, Zhengzhou, Henan 450052, P.R. China

E-mail: ybh20022002@163.com

Key words: nucleostemin, microarray, gene expression profiling, NB4 undifferentiated properties of self-renewal certain types of stem cell $(1,2)$ as well as germ cell tumors (3). Furthermore, NS is abundantly expressed in numerous tumor types, including prostate cancer (4), esophageal cancer (5), breast carcinoma (6) and gastric adenocarcinoma (7). Elevated NS expression is associated with poor prognosis of patients with various types of cancer $(8,9)$. Furthermore, knockdown of NS was shown to inhibit cell proliferation as well as induce cell cycle arrest and apoptosis $(6,10-13)$. NS is therefore a potential biomarker for tumor diagnosis and prognosis $(7,14)$.

Originally, NS was reported to combine with p53 to inhibit its function as a tumor suppressor (1). However, subsequent studies have revealed an additional p53-independent role for NS (15-17). It has been reported that NS regulates the cell cycle by modulating the stability of ARF tumor suppressor (18). However, to date, the detailed mechanism of the p53-independent NS pathway has remained elusive.

Patients with wild-type p53 tumors generally have a better prognosis than those p53-null or p53-mutant tumors; however, the latter represent the majority of tumors, which is a reason for drug-resistance and poor therapeutic effects (19). Thus, it is urgent to explore effective treatment targets for tumors which are p53-null or p53-mutant. A previous study by our group has performed gene expression profiling of the p53-null HL-60 leukemia cell line following NS knockdown (20). In order to further explore the p53-independent NS pathway, the present study subjected the p53-mutant NB4 leukemia cell line to DNA microarray analysis and gene expression profiling following NS knockdown. The present study shed light on the mechanisms of the p53-independent NS pathway in NB4 cells and provided a foundation for the discovery of promising targets for the treatment of p53-mutant leukemia.

\section{Materials and methods}

Cell culture. NB4 cells (GeneChem Co., Ltd., Shanghai, China) were maintained in RPMI-1640 medium (Gibco; Thermo Fisher Scientific, Inc., Waltham, MA, USA) supplemented with $10 \%$ fetal bovine serum (FBS; Gibco; Thermo Fisher Scientific, Inc.), $100 \mathrm{U} / \mathrm{ml}$ penicillin and $100 \mu \mathrm{g} / \mathrm{ml}$ streptomycin at $37^{\circ} \mathrm{C}$ in a humidified atmosphere containing $5 \% \mathrm{CO}_{2}$. The medium was replaced every two days. 
Table I. Sequences of the two single-stranded DNA oligonucleotides.

ID

Sequence $\left(5^{\prime}-3^{\prime}\right)$

Single-stranded

DNA oligo 1

Single-stranded

DNA oligo 2

CCGGAGCAAGTATTGAAGTAGTAAACTCGAGTTTACTACTTCAATACTTGCTTTTTTG

AATTCAAAAACAAGTATTGAAGTAGTAAACTCGAGTTTACTACTTCAATACTTGCT

Lentiviral NS-small interfering (si)RNA vector construction, packaging and transfection. The siRNA target sequence (5'-CAAGTATTGAAGTAGTAAA-3') for the NS gene (Genbank ID, NM_004196) was designed by GeneChem Co., Ltd. The two different single-stranded DNA oligonucleotides (Table I, designed by GeneChem Co., Ltd.) were matched to generate the NS-siRNA constructs by being dissolved in buffer, placed in $90^{\circ} \mathrm{C}$ water bath for $15 \mathrm{~min}$ and then naturally cooled to room temperature. Then the NS-siRNA constructs were inserted into the green fluorescent protein-labelled lentiviral expression vector GV248 (Genechem Co., Ltd.) to form the recombinant vector named NS-RNAi-GV248 vector. Next, the recombinant NS-RNAi-GV248 vectors were transformed into competent Escherichia coli cells (GeneChem Co., Ltd.) and then verified by DNA sequencing using 3730XL Genetic analyzer (Applied Biosystems, Thermo Fisher Scientific, Inc.). Subsequently, the recombinant vectors NS-RNAi-GV248, the packaging vectors pHelper 1.0 and pHelper 2.0 (GeneChem Co., Ltd.) were co-transfected into 293T cells (GeneChem Co., Ltd.). The packaged vectors were collected from the supernatants of the cell culture medium at $48 \mathrm{~h}$ after transfection. Then the Lentiviral Purification kit (GeneChem Co., Ltd.) was used to concentrate and purify the packaged recombinant lentiviral vectors according to the manufacturer's protocol.

For lentiviral transfection, $1 \times 10^{6} \mathrm{NB} 4$ cells in the logarithmic growth phase were seeded into six-well plates with $2 \mathrm{ml}$ fresh medium well. According to the titer of NB4 cells $\left(4 \times 10^{8} \mathrm{ml}\right)$ and multiplicity of infection (MOI, 30), $80 \mu \mathrm{l}$ of lentivirus were added to each well. A negative control group treated with lentiviral vectors containing negative control sequence: Sense 5'-UUCUCCGAACGUGUCACG UTT-3'; antisense 5'-ACGUGACACGUUCGGAGAATT-3' (GeneChem Co., Ltd.) and a blank control group without any lentivirus treatment was also established. At $16 \mathrm{~h}$ after infection, the culture medium was replaced with pure medium and at $72 \mathrm{~h}$ after infection, the cells were observed under a fluorescence microscope (Eclipse TS100; Nikon Corporation, Tokyo, Japan) to evaluate the transfection efficiency.

RNA extraction and reverse-transcription quantitative polymerase chain reaction analysis $(R T-q P C R)$. At $96 \mathrm{~h}$ after transfection, $5-10 \times 10^{6}$ cells per group were collected and total RNA was isolated using TRIzol reagent (Invitrogen; Thermo Fisher Scientific, Inc.) according to the manufacturer's protocol. The total extracted RNA was used to synthesize cDNA by reverse transcription reaction using the PrimeScript RT Reagent kit with gDNA Eraser (Takara Bio, Inc., Otsu, Japan). PCR amplification of NS, GAPDH,
Table II. Primer pairs used for quantitative polymerase chain reaction analysis.

\begin{tabular}{ll}
\hline Gene & \multicolumn{1}{c}{ Primer pair } \\
\hline CCND2 & F: 5'-ATTTCAGGCACAACGATA-3' \\
& R: 5'-ATTTGCTGATGGCTTCTC-3' \\
CHOP & F: 5'-CTGACCAGGGAAGTAGAGG-3' \\
& R: 5'-TGCGTATGTGGGATTGAG-3' \\
MT1E & F: 5'-GTGGGCTGTGCCAAGTGT-3' \\
& R: 5'-CAGCAAATGGCTCAGTGTT-3' \\
MT1F & F: 5'-CGACTGATGCCAGGACAA-3' \\
& R: 5'-CAAATGGGTCAAGGTGGT-3' \\
MAPK9 & F: 5'-CTGCGTCACCCATACATCAC-3' \\
& R: 5'-CTTTCTTCCAACTGGGCATC-3' \\
GAPDH & F: 5'-TGACTTCAACAGCGACACCCA-3' \\
& R: 5'-CACCCTGTTGCTGTAGCCAAA-3' \\
NS & F: 5'-TAGAGGTGTTGGATGCCAGAG-3' \\
& R: 5'-CACGCTTGGTTATCTTCCCTTTA-3'
\end{tabular}

F, forward; R, reverse.

CCND2, CHOP, MTIE, MTIF and MAPK9 was performed in an ABI7500 quantitative real-time PCR instrument (Thermo Fisher Scientific, Inc.) using the SYBR Premix Ex Taq II (Tli RNaseH Plus) kit (Takara Bio, Inc.) and the corresponding primers as listed in Table II were obtained from Sangon Biotech Co., Ltd. (Shanghai, China). The following thermocycling conditions were used: $95^{\circ} \mathrm{C}$ for $30 \mathrm{sec} ; 95^{\circ} \mathrm{C}$ for $5 \mathrm{sec}, 60^{\circ} \mathrm{C}$ for $34 \mathrm{sec}, 40$ cycles; $95^{\circ} \mathrm{C}$ for $15 \mathrm{sec}, 60^{\circ} \mathrm{C}$ for $1 \mathrm{~min}, 95^{\circ} \mathrm{C}$ for $15 \mathrm{sec}$. The PCR products were quantified using the $2^{-\Delta \Delta C q}$ method (21)

Microarray hybridization and data processing. For each treatment group of cells, the total extracted RNA was purified using an RNase Mini kit (cat. no. 74104; Qiagen, Hilden, Germany) and reversely transcribed into cDNA. Cy3-labelled cRNA was synthesized from cDNA using the Quick Amp Labeling kit, One-Color (cat. no. 5190-0442; Agilent Technologies, Inc., Santa Clara, CA, USA). The purified labelled cRNA was then subjected to hybirdization using Agilent $4 \times 44 \mathrm{~K}$ Human Whole-Genome 60-mer oligonucleotide microarrays with utilization of the Agilent Gene Expression Hybridization kit (cat. no. 5188-5242; Agilent Technologies, Inc.) following the manufacturer's instructions. 
An Agilent DNA microarray scanner (cat. no. G2565BA; Agilent Technologies, Inc.) was used to scan the microarrays, with the parameters set as follows: Green photomultiplier tube, external data representation (XDR) Hi 100\% and XDR Lo 10\%; scan resolution, $5 \mu \mathrm{m}$. Next, the acquired microarray images were analyzed using Feature Extraction v 11.01.1 software (Agilent Technologies, Inc.), and the resulting text files extracted from it were further analyzed by GeneSpring GX v 12.0 software (Agilent Technologies, Inc.). The data were normalized through logarithmic transformation. Genes with low expression were removed genes detected in all samples were selected for further data analysis. Only genes with a fold change $\geq 2$ or $\leq 0.5$ were considered as differentially expressed between the experimental and the negative control groups. Finally, the differentially expressed genes were subjected to functional analysis using the Kyoto Encyclopedia of Genes and Genomes (KEGG) pathway database (http://www.genome. $\mathrm{jp} / \mathrm{kegg}$ ).

Statistical analysis. Each assay was performed in triplicate, and values are expressed as the mean \pm standard deviation. SPSS 17.0 statistical software (SPSS, Inc., Chicago, IL, USA) was used for analysis. The means of two groups were compared using Student's t-test. Fisher's exact test was applied to assess the significance in the pathway analysis. $\mathrm{P}<0.05$ was considered to indicate a statistically significant difference between values.

\section{Results}

Transfection of NB4 cells with NS-siRNA lentiviral vectors. Observation under the inverted fluorescence microscope revealed that the transfection efficiency of the lentiviral vectors was $>80 \%$ (Fig. 1). The NS mRNA expression levels in the experimental group were decreased by $\sim 81 \%$ compared with the blank control and the negative control group $(\mathrm{P}<0.05)$, as revealed by RT-qPCR. In order to minimize the off-target effect of NS-siRNA lentiviral vectors, cells from the negative control-transfected group were then subjected to DNA microarray analysis alongside the experimental group.

DNA microarray data analysis. With the filter cutoff set at a 2.0-fold change in the microarray data analysis, a total of 1,953 differentially expressed genes were identified in NB4 cells following knockdown of NS. Of these genes, 943 were upregulated and 1,010 genes were downregulated.

Confirmation of the microarray data by RT-qPCR analysis. To further confirm the reliability of the microarray data, four significantly differentially expressed genes, CCND2, CHOP, MT1E, MT1F and MAPK9, were selected for RT-qPCR analysis. The results of the RT-qPCR analysis were in general agreement with the microarray data, as they showed the same trends (Fig. 2).

Pathway analysis. The differentially expressed genes were subjected to pathway analysis based on the KEGG database. The significant pathways containing an accumulation of upregulated or downregulated genes are listed in Tables III and IV, respectively.

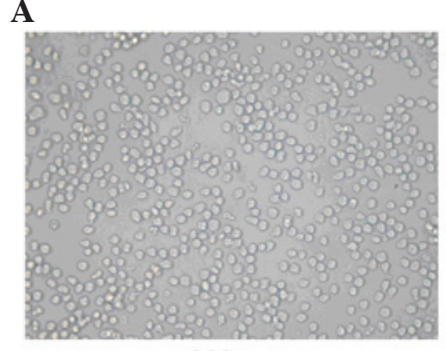

200x

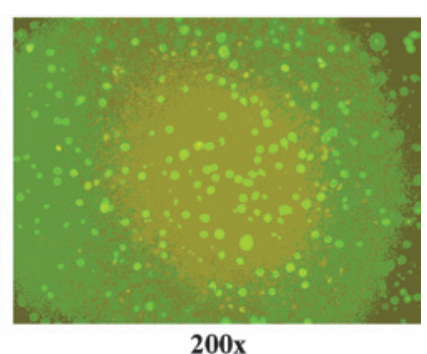

200x
B

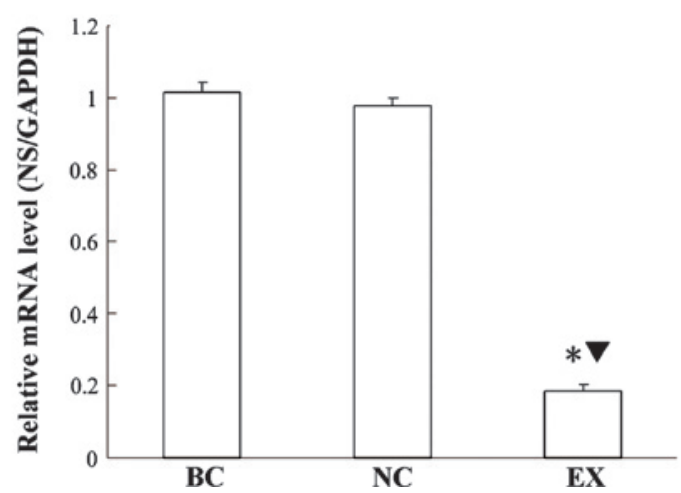

Figure 1. Confirmation of NS-siRNA transfection of NB4 cells. (A) Inverted microscopy images (left, transmitted light; right, fluorescence; magnification, $\mathrm{x} 200$ ) revealed that the majority of NB4 cells was transfected with NS-siRNA. (B) NS mRNA expression levels were detected by reverse-transcription quantitative polymerase chain reaction analysis. Values are expressed as the mean \pm standard deviation. ${ }^{*} \mathrm{P}<0.05$ compared with $\mathrm{BC}$ group; ${ }^{\mathbf{}} \mathrm{P}<0.05$ compared with $\mathrm{NC}$ group. $\mathrm{NC}$, negative control; $\mathrm{BC}$, blank control; EX, experimental group.

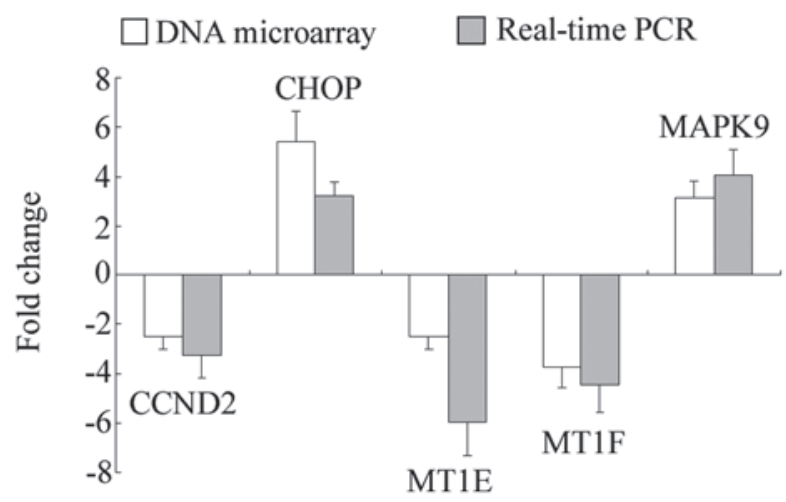

Figure 2. The reliability of the microarray data was further verified by reverse-transcription quantitative polymerase chain reaction analysis. The results of the two methods showed similar trends.

\section{Discussion}

NS is a protein required for the maintenance of stem cells, the early embryonal development and proliferation of tumor cells $(1,4,5)$. WhileNS wasinitially indicated to act viacombining with p53 (1), increasing evidence suggested the existence of an additional p53-independent NS pathway (15-17,22-24). However, the underlying mechanisms of the function of NS in p53-inactivated tumor cells have largely remained elusive. A previous study by our group reported that inhibition of the JAK/STAT, the PI3K/AKT and the RAS/RAF/MEK/ERK1/2 
Table III. Pathway analysis of upregulated genes.

\begin{tabular}{|c|c|c|c|}
\hline Pathway ID & Definition & Fisher P-value & Genes \\
\hline hsa04141 & $\begin{array}{l}\text { Protein processing in endoplasmic } \\
\text { reticulum }\end{array}$ & $6.058 \times 10^{-6}$ & $\begin{array}{l}\text { AMFR, BAX, DDIT3, DERL2, DNAJB1, } \\
\text { DNAJC3, EIF2AK3, HERPUD1, HSPA1B, } \\
\text { HSPA8, HSPH1, MAPK9, MARCH6, } \\
\text { PDIA3, PDIA4, PPP1R15A, SEC24A, } \\
\text { SEC61A2, SSR1, UBQLN1, YOD1 }\end{array}$ \\
\hline hsa04621 & $\begin{array}{l}\text { NOD-like receptor signaling } \\
\text { pathway }\end{array}$ & $1.536 \times 10^{-4}$ & $\begin{array}{l}\text { BIRC3, CCL2, CXCL2, IL1B, IL8, } \\
\text { MAPK9, NFKBIA, TAB2, TAB3, TNFAIP3 }\end{array}$ \\
\hline hsa05164 & Influenza A & $1.153 \times 10^{-3}$ & $\begin{array}{l}\text { AKT3, ATF2, CCL2, DNAJB1, DNAJC3, } \\
\text { EIF2AK3, EP300, GSK3B, HLA-DOA, } \\
\text { HLA-DRB5, HSPA1B, HSPA8, ICAM1, } \\
\text { IL1B, IL8, MAPK9, NFKBIA }\end{array}$ \\
\hline hsa05219 & Bladder cancer & $1.683 \times 10^{-3}$ & $\begin{array}{l}\text { IL8, KRAS, MMP1, NRAS, RPS6KA5, } \\
\text { THBS1, VEGFA }\end{array}$ \\
\hline hsa05166 & HTLV-I infection & $1.913 \times 10^{-3}$ & $\begin{array}{l}\text { AKT3, ATF2, ATF3, ATM, BAX, BIRC3, } \\
\text { EGR1, EGR2, EP300, FZD5, GSK3B, } \\
\text { HLA-DOA, HLA-DRB5, ICAM1, IL15, } \\
\text { KRAS, MAPK9, NFKBIA, NRAS, } \\
\text { NRP1, TBPL1, ZFP36 }\end{array}$ \\
\hline hsa04115 & p53 signaling pathway & $2.297 \times 10^{-3}$ & $\begin{array}{l}\text { ATM, BAX, BBC3, CCNE2, MDM4, } \\
\text { RRM2, SERPINE1, SESN1, THBS1 }\end{array}$ \\
\hline hsa05211 & Renal cell carcinoma & $2.541 \times 10^{-3}$ & $\begin{array}{l}\text { AKT3, ARNT, EP300, FLCN, HGF, } \\
\text { KRAS, NRAS, RAC1, VEGFA }\end{array}$ \\
\hline hsa04620 & $\begin{array}{l}\text { Toll-like receptor signaling } \\
\text { pathway }\end{array}$ & $3.649 \times 10^{-3}$ & $\begin{array}{l}\text { AKT3, CCL4, IL1B, IL8, LY96, AP3K8, } \\
\text { MAPK9, NFKBIA, RAC1, SPP1, TAB2 }\end{array}$ \\
\hline hsa05162 & Measles & $4.155 \times 10^{-3}$ & $\begin{array}{l}\text { AKT3, BBC3, CBLB, CCNE2, } \\
\text { CSNK2A1, EIF2AK3, GSK3B, } \\
\text { HSPA1B, HSPA8, IL1B, NFKBIA, } \\
\text { TAB2, TNFAIP3 }\end{array}$ \\
\hline hsa04010 & MAPK signaling pathway & $4.391 \times 10^{-3}$ & $\begin{array}{l}\text { AKT3, ATF2, CACNA1E, DDIT3, } \\
\text { DUSP1, DUSP5, HSPA1B, HSPA8, } \\
\text { IL1B, KRAS, MAP3K2, MAP3K8, } \\
\text { MAP4K3, MAP4K4, MAPK9, NRAS, } \\
\text { PPP3R1, RAC1, RPS6KA5, TAB2, TAOK1 }\end{array}$ \\
\hline hsa05323 & Rheumatoid arthritis & $5.186 \times 10^{-3}$ & $\begin{array}{l}\text { CCL2, CCL3L3, HLA-DOA, HLA-DRB5, } \\
\text { ICAM1, IL15, IL1B, IL8, MMP1, VEGFA }\end{array}$ \\
\hline hsa04660 & T-cell receptor signaling pathway & $5.655 \times 10^{-3}$ & $\begin{array}{l}\text { AKT3, CBLB, GSK3B, KRAS, MAP3K8, } \\
\text { MAPK9, NCK1, NFKBIA, NRAS, } \\
\text { PPP3R1, PTPRC }\end{array}$ \\
\hline hsa05200 & Pathways in cancer & $1.067 \times 10^{-2}$ & $\begin{array}{l}\text { AKT3, ARNT, BAX, BIRC3, CBLB, } \\
\text { CCDC6, CCNE2, CSF1R, EP300, FZD5, } \\
\text { GSK3B, HGF, IL8, ITGA6, KRAS, } \\
\text { MAPK9, MITF, MMP1, NFKBIA, NRAS, } \\
\text { RAC1, TPR, VEGFA }\end{array}$ \\
\hline hsa04662 & B-cell receptor signaling pathway & $1.330 \times 10^{-2}$ & $\begin{array}{l}\text { AKT3, GSK3B, KRAS, LILRB3, NFKBIA, } \\
\text { NRAS, PPP3R1, RAC1 }\end{array}$ \\
\hline hsa05144 & Malaria & $1.966 \times 10^{-2}$ & CCL2, HGF, ICAM1, IL1B, IL8, THBS1 \\
\hline hsa05014 & Amyotrophic lateral sclerosis (ALS) & $2.338 \times 10^{-2}$ & $\begin{array}{l}\text { ALS2, BAX, PPP3R1, RAB5A, } \\
\text { RAC1, TNFRSF1B }\end{array}$ \\
\hline hsa05145 & Toxoplasmosis & $2.458 \times 10^{-2}$ & $\begin{array}{l}\text { AKT3, BIRC3, HLA-DOA, HLA-DRB5, } \\
\text { HSPA1B, HSPA8, ITGA6, LY96, MAPK9, } \\
\text { NFKBIA, TAB2 }\end{array}$ \\
\hline hsa04210 & Apoptosis & $2.818 \times 10^{-2}$ & $\begin{array}{l}\text { AKT3, ATM, BAX, BIRC3, IL1B, } \\
\text { IL1RAP, NFKBIA, PPP3R1 }\end{array}$ \\
\hline hsa04012 & ErbB signaling pathway & $2.994 \times 10^{-2}$ & $\begin{array}{l}\text { ABL2, AKT3, CBLB, GSK3B, KRAS, } \\
\text { MAPK9, NCK1, NRAS }\end{array}$ \\
\hline
\end{tabular}


Table III. Continued.

\begin{tabular}{|c|c|c|c|}
\hline Pathway ID & Definition & Fisher P-value & Genes \\
\hline hsa05132 & Salmonella infection & $2.995 \times 10^{-2}$ & $\begin{array}{l}\text { CCL3L3, CCL4, CXCL2, IL1B, IL8, } \\
\text { MAPK9, PKN2, RAC1 }\end{array}$ \\
\hline hsa05142 & $\begin{array}{l}\text { Chagas disease (American } \\
\text { trypanosomiasis) }\end{array}$ & $3.111 \times 10^{-2}$ & $\begin{array}{l}\text { AKT3, CCL2, CCL3L3, GNAQ, IL1B, } \\
\text { IL8, MAPK9, NFKBIA, SERPINE1 }\end{array}$ \\
\hline hsa05216 & Thyroid cancer & $3.224 \times 10^{-2}$ & CCDC6, KRAS, NRAS, TPR \\
\hline hsa04722 & Neurotrophin signaling pathway & $4.179 \times 10^{-2}$ & $\begin{array}{l}\text { AKT3, ARHGDIB, BAX, GSK3B, KRAS, } \\
\text { MAPK9, NFKBIA, NRAS, RAC1, } \\
\text { RPS6KA5 }\end{array}$ \\
\hline hsa04380 & Osteoclast differentiation & $4.372 \times 10^{-2}$ & $\begin{array}{l}\text { AKT3, CSF1R, GAB2, IL1B, LILRB3, } \\
\text { MAPK9, MITF, NFKBIA, RAC1, TAB2 }\end{array}$ \\
\hline hsa05210 & Colorectal cancer & $4.585 \times 10^{-2}$ & $\begin{array}{l}\text { AKT3, BAX, GSK3B, KRAS, MAPK9, } \\
\text { RAC1 }\end{array}$ \\
\hline
\end{tabular}

hsa, Homo sapiens.

Table IV. Pathway analysis of downregulated genes.

\begin{tabular}{|c|c|c|c|}
\hline Pathway ID & Definition & Fisher-P-value & Genes \\
\hline hsa04978 & Mineral absorption & $8.318 \times 10^{-4}$ & $\begin{array}{l}\text { ATP1A4, MT1B, MT1E, MT1F, MT1H, } \\
\text { MT1X, MT2A, SLC31A1 }\end{array}$ \\
\hline hsa00920 & Sulfur metabolism & $1.338 \times 10^{-3}$ & BPNT1, SULT1A2, SULT1A4, SUOX \\
\hline hsa04146 & Peroxisome & $3.678 \times 10^{-3}$ & $\begin{array}{l}\text { ACOX1, AMACR, CRAT, DHRS4, } \\
\text { HMGCL, IDH1, IDH2, PEX6, PXMP4 }\end{array}$ \\
\hline hsa03013 & RNA transport & $7.928 \times 10^{-3}$ & $\begin{array}{l}\text { C9ORF23, DDX39B, EIF4B, EIF4E2, } \\
\text { EIF4G3, ELAC1, GEMIN4, GEMIN6, } \\
\text { NCBP1, PABPC1L, PRMT5, RPP30, } \\
\text { XPO5 }\end{array}$ \\
\hline hsa00510 & N-Glycan biosynthesis & $1.269 \times 10^{-2}$ & $\begin{array}{l}\text { B4GALT2, DOLK, FUT8, MAN1B1, } \\
\text { MAN1C1, MGAT1 }\end{array}$ \\
\hline hsa00051 & Fructose and mannose metabolism & $1.339 \times 10^{-2}$ & ALDOC, GMPPA, KHK, PMM2, TSTA3 \\
\hline hsa03008 & Ribosome biogenesis in eukaryotes & $1.843 \times 10^{-2}$ & $\begin{array}{l}\text { C9ORF23, GNL3, GNL3L, IMP4, } \\
\text { NOL6, NOP56, RPP30, UTP14A }\end{array}$ \\
\hline hsa00533 & $\begin{array}{l}\text { Glycosaminoglycan biosynthesis - keratan } \\
\text { sulfate }\end{array}$ & $2.009 \times 10^{-2}$ & B4GALT2, FUT8, ST3GAL3 \\
\hline hsa04622 & RIG-I-like receptor signaling pathway & $2.255 \times 10^{-2}$ & $\begin{array}{l}\text { CASP8, DAK, DHX58, IRF3, MAVS, } \\
\text { NLRX1, RIPK1 }\end{array}$ \\
\hline hsa00020 & Citrate cycle (tricarboxylic acid cycle) & $3.015 \times 10^{-2}$ & IDH1, IDH2, PCK2, SDHA \\
\hline hsa04623 & Cytosolic DNA-sensing pathway & $3.642 \times 10^{-2}$ & $\begin{array}{l}\text { IRF3, MAVS, POLR1C, POLR3C, } \\
\text { POLR3H, RIPK1 }\end{array}$ \\
\hline hsa00531 & Glycosaminoglycan degradation & $3.806 \times 10^{-2}$ & GALNS, HGSNAT, NAGLU \\
\hline hsa00010 & Glycolysis/Gluconeogenesis & $4.438 \times 10^{-2}$ & $\begin{array}{l}\text { AKR1A1, ALDOC, ENO3, LDHA, } \\
\text { PCK2, PGAM1 }\end{array}$ \\
\hline hsa03015 & mRNA surveillance pathway & $4.988 \times 10^{-2}$ & $\begin{array}{l}\text { CPSF6, DDX39B, NCBP1, PABPC1L, } \\
\text { PAPOLA, PCF11, PPP2R1A }\end{array}$ \\
\hline
\end{tabular}

hsa, Homo sapiens.

pathways, as well as the activation of the p38MAPK and JNK pathways may participate in the induction of apoptosis following NS knockdown in p53-null HL-60 cells (20).

The present study further explored the mechanisms of the function of the p53-independent function of NS by using the p53-mutant NB4 leukemia cell line. Gene expression profiling indicated that a large number of genes were aberrantly expressed in NB4 cells following knockdown of NS.

Subsequent pathway analysis of upregulated genes revealed that protein processing in the endoplasmic reticulum (ER) was 


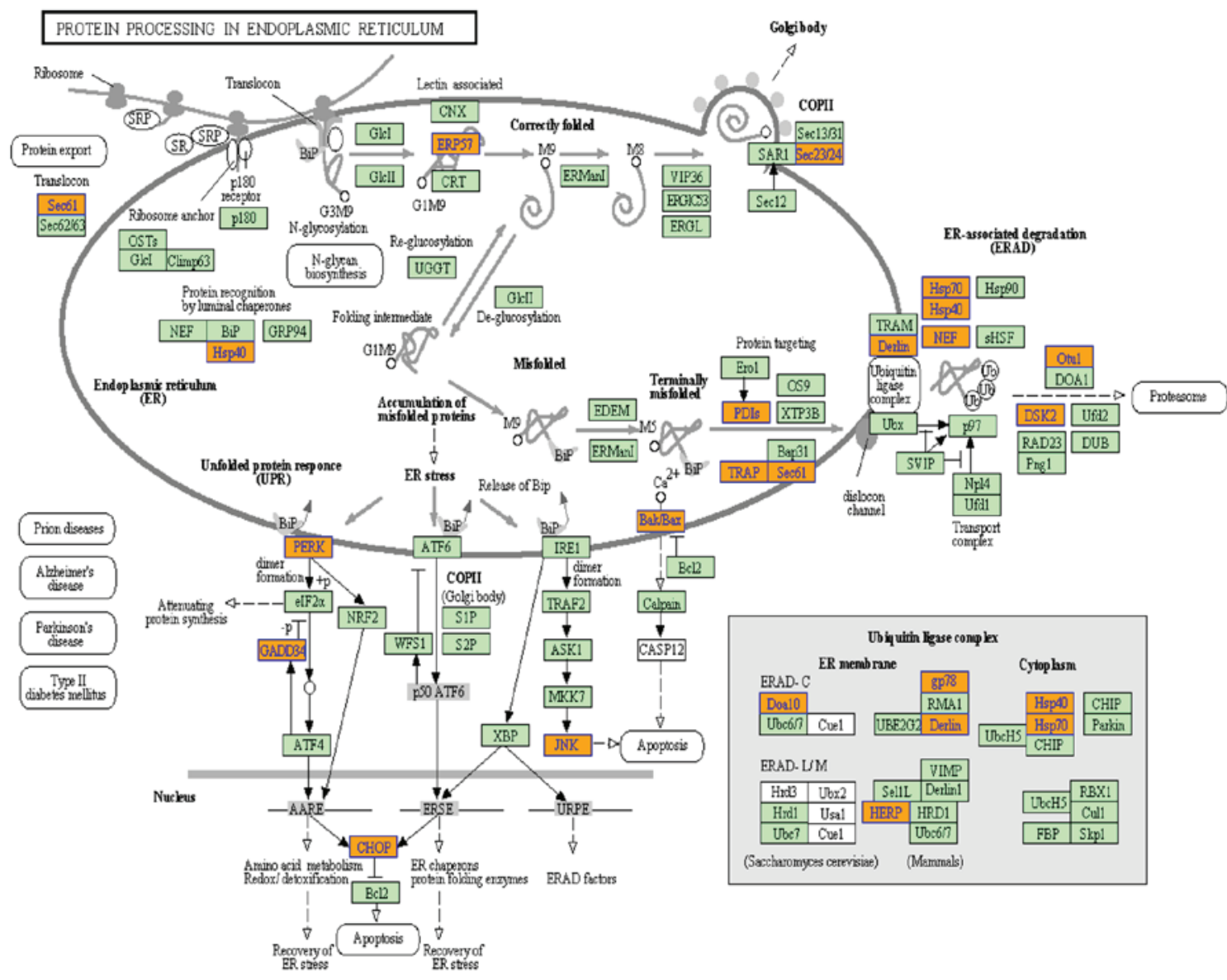

Figure 3. Protein processing in the endoplasmic reticulum (orange nodes are associated with upregulated or only whole dataset genes and green nodes have no significance). The diagram was produced using software developed by the Kanehisa Laboratory.

the most significant KEGG pathway. Under normal physiological conditions, the ER only transports correctly folded proteins to the Golgi-apparatus, while misfolded proteins are extracted for ubiquitin-dependent ER-associated degradation (ERAD) (25). However, insufficient degradation leads to ER stress due to accumulation of misfolded proteins, and the unfolded protein response (UPR) is then activated to maintain the homeostasis of the ER (26). When misfolded protein stress exceeds the tolerance threshold of the ER, and the UPR is insufficient for the maintenance of homeostasis, cell apoptosis is activated, which is referred to as ER stress-induced apoptosis $(27,28)$. PERK, IRE1 and ATF6 are three main sensor proteins located on the ER membrane, which are activated as part of the UPR by dissociation from GRP78 and relieve the stress through a series of pathways. As illustrated in Fig. 3, a number of upregulated genes were associated with the ERAD process, which indicated that ER stress may have increased in NB4 cells after knockdown of NS. Furthermore, prolonged ER stress is able to induce apoptosis (29). However, further studies are required to determine whether downregulation of NS may directly activate apoptosis in NB4 cells. CHOP and JNK are key mediators during ER stress-induced apoptosis (30). In the present study, PERK, CHOP and JNK (MAPK9) were all upregulated. Therefore, it is indicated that the p53-independent NS pathway may also be associated with increases in ER stress and an imbalance of ER homeostasis.
In addition, several of the upregulated genes were enriched in the MAPK signaling pathway (Fig. 4), which was a similar finding to previous observations in HL-60 cells (20). MAPK pathways mainly consist of the JNK, the RAS/RAF/MEK/ERK2 and the p38MAPK pathways, while activation of JNK and p38MAPK pathways is known to induce cell apoptosis (31). In contrast to the findings in HL-60 cells, only JNK(MAPK9) was upregulated in NB4 cells following NS knockdown. Therefore, activation of the JNK pathway was another effect of NS knockdown in NB4 cells, indicating that NS may exert its effects via the NS pathway.

Analysis of downregulated genes showed that mineral absorption was most significant pathway. The key genes in this pathway were metallothioneins (MTs). MT genes are a family of cysteine-rich proteins, which are closely linked and mainly comprise 11 MT-1 genes (including MT-1A, -B, -E - L and -X) and one gene for other MT isoforms (MT-2A, MT-3 and MT-4) (32). MT-1 and MT-2 isoforms are widely expressed in numerous cell types. MT-3 is associated with neuronal cells; it is also called neuronal growth-inhibitory factor and inhibits the outgrowth of neuronal cells (33). MT-4 is primarily expressed on certain squamous epithelial cells (34). The differentially expressed MT genes in the present study were mainly MT-1 genes, including MT-1A, MT-1B, MT-1E, MT-1F, MT-1H, MT-1L and MT-1X. MTs participate in zinc and copper homeostasis, protection against heavy metal 


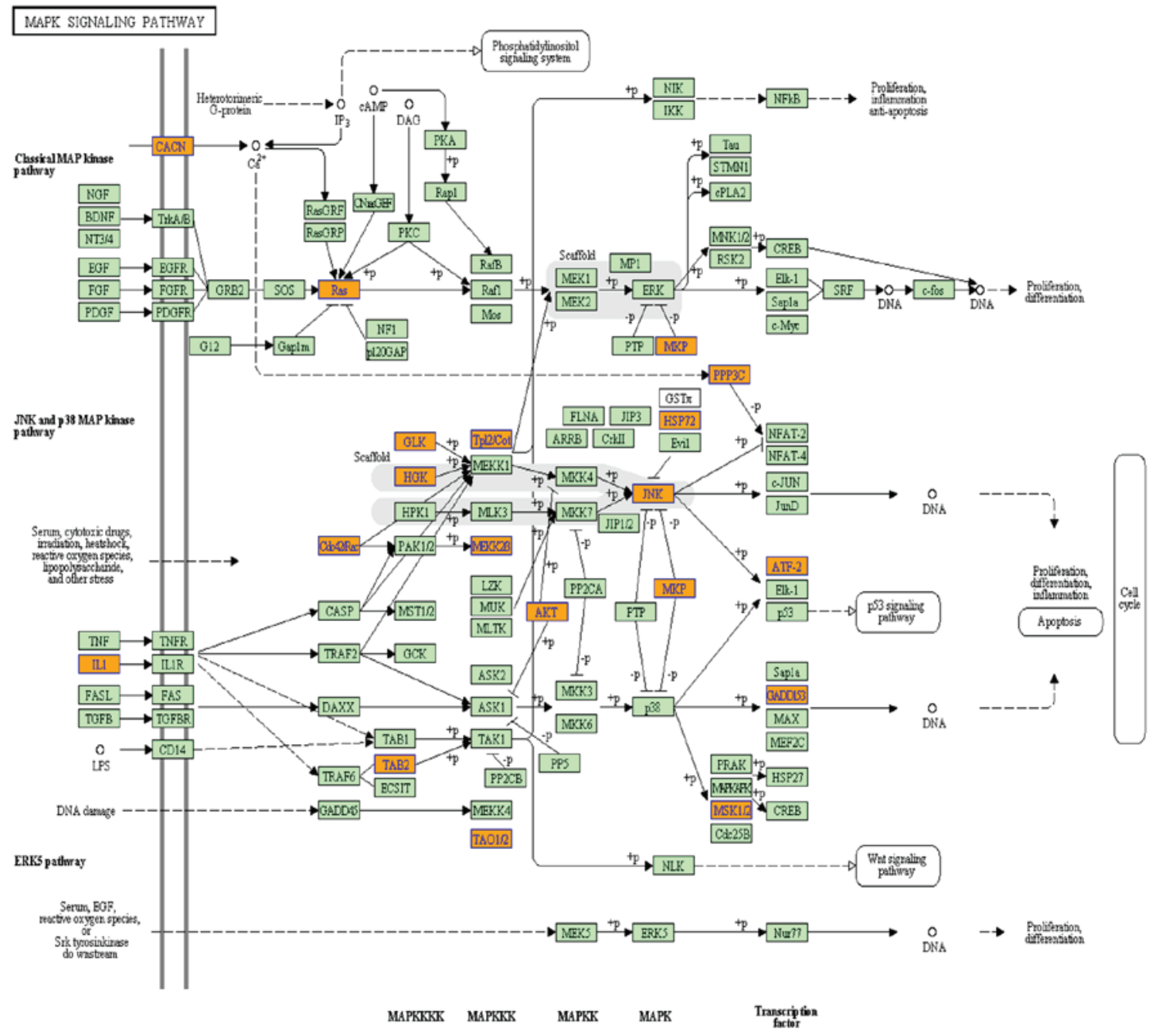

Figure 4. MAPK signaling pathway (orange nodes are associated with upregulated or only whole dataset genes and green nodes have no significance). The diagram was produced using software developed by the Kanehisa Laboratory.

toxicity and oxidative damage. As zinc deficiency is associated with oxidative stress (35), downregulation of MTs may disturb the homeostasis of zinc and copper, which increases oxidative stress in cells. Furthermore, as MTs are rich in sulfhydryl and have a high anti-oxidant capacity, they are able to effectively eliminate superoxide and hydroxyl radicals (36). Therefore, downregulation of MT expression may result in oxidative stress due to the absence of anti-oxidants, which may be an underlying mechanism for the imbalance of ER homeostasis indicated by the present study.

In addition, MTs are closely linked with malignant tumors. Metal-regulatory transcription factor-1 (MTF-1) is the only known mediator of the metal responsiveness of MTs and is able to regulate the expression of MTs $(32,37,38)$. MTF-1 is elevated in numerous tumor types, including lung, breast, and cervical carcinoma-derived cell lines (39), which supports the link between MTs and tumors. MTs have been shown to be distinctly elevated in rapidly growing tissues such as the neonatal liver, suggesting that MTs are important in cell proliferation $(40,41)$. Furthermore, increased expression of MTs is associated with drug resistance $(42,43)$, anti-apoptotic capacity $(44,45)$, breast cancer prognosis $(46)$ and differentiation of thyroid tumor cells (47). Thus, the DNA microarray data analysis indicated that following a knockdown of NS in NB4 cells, diminished proliferation and low tumorigenic capacity may occur due to downregulation of MTs. This requires further verification in future studies.

In the present study, a further significant pathway with accumulation of downregulated genes was the peroxisome pathway. Inhibition of the peroxisome pathway reduces the synthesis of peroxisome, which is an intracellular organelle located in the cytoplasm and contains an abundance of enzymes, including catalase, oxidase and peroxidase. Therefore, decreased synthesis of peroxisome reduces these enzymes, which may influence the redox state of the cells or the ER, causing imbalance of ER homeostasis.

In addition, pathway analysis of downregulated genes showed that the pathways involved were mostly associated with biosubstance synthesis and metabolism, including sulfur metabolism, RNA transport, N-glycan biosynthesis, fructose and mannose metabolism, ribosome biogenesis in eukaryotes, glycosaminoglycan biosynthesis and citrate cycle. This indicated that the biosynthesis and metabolism of NB4 cells was reduced following knockdown of NS expression $(48,49)$.

In conclusion, gene expression profiling analysis of NB4 cells following knockdown of NS revealed a large number of 
differentially expressed genes. Pathway analysis indicated that ER stress may increase in NB4 cells after NS inhibition, which may cause an imbalance of ER homeostasis; furthermore, the JNK pathway was activated. In addition, biosubstance synthesis and metabolism in NB4 cells was reduced following NS knockdown. The present study provided insight into the underlying mechanism of the p53-independent NS signaling pathway, which may be utilized for the development of novel treatments for $\mathrm{p} 35$-null/mutated cancer types.

\section{Acknowledgements}

The present study was funded by the National Natural Science Foundation of China (no. 81271911) and the Key Projects of Medical Science and Technology of Henan Province (no. 201002006).

\section{References}

1. Tsai RY and McKay RD: A nucleolar mechanism controlling cell proliferation in stem cells and cancer cells. Genes Dev 16 2991-3003, 2002.

2. Liu SJ, Cai ZW, Liu YJ, Dong MY, Sun LQ, Hu GF, Wei YY and Lao WD: Role of nucleostemin in growth regulation of gastric cancer, liver cancer and other malignancies. World J Gastroenterol 10: 1246-1249, 2004.

3. Uema N, Ooshio T, Harada K, Naito M, Naka K, Hoshii T, Tadokoro Y, Ohta K, Ali MA, Katano M, et al: Abundant nucleostemin expression supports the undifferentiated properties of germ cell tumors. Am J Pathol 183: 592-603, 2013.

4. Liu RL, Xu Y, Zhang ZH, Wang M, Sun JT, Qi SY, Zhang Y and Li SZ: Expression of nucleostemin in prostate cancer tissues and its clinical significance. Natl J Androl 14: 418-422, 2008 (In Chinese)

5. Zhang GY, Yin L, Li SL, Xing WY, Zhao QM, Le XP, Gao DL, Chen KS, Zhang YH and Zhang QX: Expression of nucleostemin mRNA and protein in the esophageal squamous cell carcinoma. Chin J Oncol 30: 125-128, 2008 (In Chinese).

6. Guo Y, Liao YP, Zhang D, Xu LS, Li N, Guan WJ and Liu CQ: In vitro study of nucleostemin as a potential therapeutic target in human breast carcinoma SKBR-3 cells. Asian Pac J Cancer Prev 15: 2291-2295, 2014.

7. Asadi MH, Derakhshani A and Mowla SJ: Concomitant upregulation of nucleostemin and downregulation of Sox 2 and Klf4 in gastric adenocarcinoma. Tumour Biol 35: 7177-7185, 2014.

8. Kobayashi T, Masutomi K, Tamura K, Moriya T, Yamasaki T, Fujiwara Y, Takahashi S, Yamamoto J and Tsuda H: Nucleostemin expression in invasive breast cancer. BMC Cancer 14: 215, 2014.

9. You Y, Li X, Zheng J, Wu Y, He Y, Du W, Zou P and Zhang M: Transcript level of nucleostemin in newly diagnosed acute myeloid leukemia patients. Leuk Res 37: 1636-1641, 2013.

10. Sijin L, Ziwei C, Yajun L, Meiyu D, Hongwei Z, Guofa H, Siguo L, Hong G, Zhihong Z, Xiaolei L, et al: The effect of knocking-down nucleostemin gene expression on the in vitro proliferation and in vivo tumorigenesis of HeLa cells. J Exp Clin Cancer Res 23: 529-538, 2004

11. Ma H and Pederson T: Depletion of the nucleolar protein nucleostemin causes G1 cell cycle arrest via the p53 pathway. Mol Biol Cell 18: 2630-2635, 2007.

12. Liu RL, Zhang ZH, Zhao WM, Wang M, Qi SY, Li J, Zhang Y, $\mathrm{Li} \mathrm{SZ}$ and $\mathrm{Xu} \mathrm{Y}$ : Expression of nucleostemin in prostate cancer and its effect on the proliferation of PC-3 cells. Chin Med J (Engl) 121: 299-304, 2008.

13. Seyed-Gogani N, Rahmati M, Zarghami N, Asvadi-Kermani I, Hoseinpour-Feyzi MA and Moosavi MA: Nucleostemin depletion induces post-g1 arrest apoptosis in chronic myelogenous leukemia k562 cells. Adv Pharm Bull 4: 55-60, 2014.

14. Amini S, Fathi F, Mobalegi J, Sofimajidpour H and Ghadimi T: The expressions of stem cell markers: Oct4, Nanog, Sox2, nucleostemin, Bmi, Zfx, Tcl1, Tbx3, Dppa4 and Esrrb in bladder, colon and prostate cancer and certain cancer cell lines. Anat Cell Biol 47: 1-11, 2014.
15. Beekman C, Nichane M, De Clercq S, Maetens M, Floss T, Wurst W, Bellefroid E and Marine JC: Evolutionarily conserved role of nucleostemin: Controlling proliferation of stem/progenitor cells during early vertebrate development. Mol Cell Biol 26: 9291-9301, 2006

16. Jafarnejad SM, Mowla SJ and Matin MM: Knocking-down the expression of nucleostemin significantly decreases rate of proliferation of rat bone marrow stromal stem cells in an apparently p53-independent manner. Cell Prolif 41: 28-35, 2008.

17. Nikpour P, Mowla SJ, Jafarnejad SM, Fischer U and Schulz WA: Differential effects of Nucleostemin suppression on cell cycle arrest and apoptosis in the bladder cancer cell lines 5637 and SW1710. Cell Prolif 42: 762-769, 2009.

18. Lo D, Zhang Y, Dai MS, Sun XX, Zeng SX and Lu H: Nucleostemin stabilizes ARF by inhibiting the ubiquitin ligase ULF. Oncogene 34: 1688-1697, 2015.

19. Li X, Zhou J, Chen ZR and Chng WJ: P53 mutations in colorectal cancer-molecular pathogenesis and pharmacological reactivation. World J Gastroenterol 21: 84-93, 2015.

20. Sun X, Jia Y, Wei Y, Liu S and Yue B: Gene expression profiling of HL-60 cells following knockdown of nucleostemin using DNA microarrays. Oncol Rep 32: 739-747, 2014.

21. Livak KJ and Schmittgen TD: Analysis of relative gene expression data using real-time quantitative PCR and the 2(-Delta Delta C(T)) method. Methods 25: 402-408, 2001.

22. Liu R, Zhang Z and $\mathrm{Xu} \mathrm{Y}$ : Downregulation of nucleostemin causes G1 cell cycle arrest via a p53-independent pathway in prostate cancer PC-3 cells. Urol Int 85: 221-227, 2010.

23. Zwolinska AK, Heagle Whiting A, Beekman C, Sedivy JM and Marine JC: Suppression of Myc oncogenic activity by nucleostemin haploinsufficiency. Oncogene 31: 3311-3321, 2012.

24. Paridaen JT, Janson E, Utami KH, Pereboom TC, Essers PB, Rooijen C, Zivkovic D and MacInnes AW: The nucleolar GTP-binding proteins $\mathrm{Gnl} 2$ and nucleostemin are required for retinal neurogenesis in developing zebrafish. Dev Biol 355: 286-301, 2011.

25. Stolz A and Wolf DH: Endoplasmic reticulum associated protein degradation: A chaperone assisted journey to hell. Biochim Biophys Acta 1803: 694-705, 2010.

26. Määttänen P, Gehring K, Bergeron JJ and Thomas DY: Protein quality control in the ER: The recognition of misfolded proteins. Semin Cell Dev Biol 21: 500-411, 2010.

27. Fu XL and Gao DS. Endoplasmic reticulum proteins quality control and the unfolded protein response: The regulative mechanism of organisms against stress injuries. Biofactors 40: 569-585, 2014.

28. Lu W, Hagiwara D, Morishita Y, Tochiya M, Azuma Y, Suga H, Goto M, Banno R, Sugimura Y, Oyadomari S, et al: Unfolded protein response in hupothalamic cultures of wild-type and ATF6 $\alpha$-knockout mice. Neurosci Lett 612: 199-203, 2015.

29. Rao RV, Castro-Obregon S, Frankowski H, Schuler M, Stoka V, Del RG, Bredesen DE and Ellerby HM: Coupling endoplasmic reticulum stress to the cell death program. An Apaf-1-independent intrinsic pathway. J Biol Chem 277: 21836-21842, 2002.

30. Szegezdi E, Logue SE, Gorman AM and Samali A: Mediators of endoplasmic reticulum stress-induced apoptosis. EMBO Rep 7: 880-885, 2006

31. Raman M, Chen W and Cobb MH: Differential regulation and properties of MAPKs. Oncogene 26: 3100-3112, 2007.

32. Huang ZX: Neuronal growth-inhibitory factor (metallothionein-3): A unique metalloprotein. FEBS J 277: 2911, 2010.

33. Vašák M and Meloni G: Chemistry and biology of mammalian metallothioneins. J Biol Inorg Chem 16: 1067-1078, 2011.

34. Eide DJ: The oxidative stress of zinc deficiency. Metallomics 3: 1124-1129, 2011.

35. Miura T, Muraoka S and Ogiso T: Antioxidant activity of metallothionein compared with reduced glutathione. Life Sci 60: 301-309, 1997.

36. Ghoshal K and Jacob ST: Regulation of metallothionein gene expression. Prog Nucleic Acid Res Mol Biol 66: 357-384, 2001.

37. Günes C, Heuchel R, Georgiev O, Müller KH, Lichtlen P, Bluthmann H, Marino S, Aguzzi A and Schaffner W: Embryonic lethality and liver degeneration in mice lacking the metal-responsive transcriptional activator MTF-1. EMBO J 17: 2846-2854, 1998.

38. Klassen RB, Crenshaw K, Kozyraki R, Verroust PJ, Tio L, Atrian S, Allen PL and Hammond TG: Megalin mediates renal uptake of heavy metal metallothionein complexes. Am J Physiol Renal Physiol 287: F393-F403, 2004. 
39. Shi Y, Amin K, Sato BG, Samuelsson SJ, Sambucetti L, Haroon ZA, Laderoute K and Murphy BJ: The metal-responsive transcription factor-1 protein is elevated in human tumors. Cancer Biol Ther 9: 469-476, 2010.

40. Cherian MG and Apostolova MD: Nuclear localization of metallothionein during cell proliferation and differentiation. Cell Mol Biol (Noisy-le-grand) 46: 347-356, 2000.

41. Ogra Y and Suzuki KT: Nuclear trafficking of metallothionein: Possible mechanisms and current knowledge. Cell Mol Biol (Noisy-le-grand) 46: 357-365, 2000.

42. Knipp M: Metallothioneins and platinum (II) anti-tumor compounds. Curr Med Chem 16: 522-537, 2009.

43. Boulikas T and Vougiouka M: Cisplatin and platinum drugs at the molecular level (Review). Oncol Rep 10: 1663-1682, 2003.

44. McGee HM, Woods GM, Bennett B and Chung RS: The two faces of metallothionein in carcinogenesis: Photoprotection against UVR-induced cancer and promotion of tumour survival. Photochem Photobiol Sci 9: 586-596, 2010.
45. Dutsch-Wicherek M, Sikora J and Tomaszewska R: The possible biological role of metallothionein in apoptosis. Front Biosci 13: 4029-4038, 2008.

46. Gomulkiewicz A, Podhorska-Okolow M, Szulc R, Smorag Z, Wojnar A, Zabel M and Dziegiel P: Correlation between metallothionein (MT) expression and selected prognostic factors in ductal breast cancers. Folia Histochem Cytobiol 48: 242-248, 2010.

47. Królicka A, Kobierzycki C, Puła B, Podhorska-Okołów M, Piotrowska A, Rzeszutko M, Rzeszutko W, Rabczyński J, Domosławski P, Wojtczak B, et al: Comparison of metallothionein (MT) and Ki-67 antigen expression in benign and malignant thyroid tumours. Anticancer Res 30: 4945-4949, 2010.

48. Kishton RJ and Rathmell JC: Novel therapeutic targets of tumor metabolism. Cancer J 21: 62-69, 2015.

49. Gottfried E,Kreutz M and Mackensen A: Tumor metabolism as modulator of immune response and tumor progression. Semin Cancer Biol 22: 335-341, 2012. 